\title{
Pengelolaan lembaga kearsipan di kantor surat kabar berita pagi Palembang
}

\author{
Berti Atika Putri, Kurniawati, Ade Dwi Nurrizqi
}

\begin{abstract}
This article discusses the management of archival institutions in the Palembang morning news paper office. The purpose of this paper is to find out the position of the structural side of the archive processing unit, and the archive management system and archive storage system at the Palembang Morning News Office. Data was obtained through direct observation of interviews with archival processing staff at the Palembang Morning News Office. The office implements a decentralized system which means that in each work unit it stores archives in their respective fields. And the conclusion in the Morning News Agency in Palembang was that there was no archival processing unit specifically processing the archives in the office, but they processed the archives in their respective work divisions in the office itself, while processing the archives themselves directly in their respective divisions. As well as archive storage managed through a date system.
\end{abstract}

Keywords: filing unit, archive management, archive storage

\section{Pendahuluan}

\section{Latar Belakang}

Menurut Undang-Undang (UU) Nomor 43 Tahun 2009 mengenai kearsipan, arsip adalah rekaman kegiatan atau peristiwa dalam berbagai bentuk dan media sesuai dengan perkembangan teknologi informasi dan komunikasi yang dibuat dan diterima oleh lembaga negara, pemerintahan daerah, lembaga pendidikan, perusahaan, organisasi politik, organisasi kemasyarakatan, dan perseorangan dalam pelaksanaan kehidupan bermasyarakat, berbangsa, dan bernegara (Basuki, 2015).

Terkait dengan pengelolaan kearsipan di Indonesia diatur dalam Undang-undang Republik Indonesia Nomor 43 Tahun 2009 
tentang kearsipan menerangkan bahwa yang dimaksud dengan kearsipan adalah hal-hal yang berkenaan dengan arsip (Basuki, 2015). Begitu pula dengan zaman yang semakin pesat ini, sebuah perusahaan tetap harus mengedepankan kearsipannya.

Archives have traditionally been regarded as neutral and objective repositories for authentic records of human activity against which the researcher can evaluate other more subjective sources of information (Jimerson, 2003). Dengan itu dapat di pahami bahwa suatu arsip dapat dijadikan catatan hasil kegiatan dari manusia itu sendiri, bukan hanya itu arsip juga dapat dikatakan sebagai segala kertas, buku, foto, film, rekaman suara, gambar peta, bagan atau dokumen-dokumen lain dalam segala macam bentuk dan sifatnya, asli atau salinannya, serta dengan segala penciptaanya dan yang dihasilkan atau diterima oleh suatu organisasi atau badan, sebagai bukti atas tujuan, fungsi-fungsi, kebijaksanaan, keputusan, prosedur, pekerjaan atau kegiatan pemerintahan yang lain atau karna pentingnya informasi yang terkandung didalamnya (Wursanto, 2005).

States that the most common definition of archives as: In archival terminology the word archives can have more than one meaning. Archives are non current records of an organization, institution, or individual, which are selected for preservation because of their continuing value. Its second meaning is the repository or building where archival material is stored. Its third meaning is an agency responsible for the selection, preservation, documentation and making available of archival materials. (Senturk, 2011). Jadi dapat dipahami bahwa Dalam terminologi arsip, arsip kata dapat memiliki lebih dari satu arti. Arsip adalah rekaman tidak terkini dari suatu organisasi, lembaga, atau individu, yang dipilih untuk pelestarian karena nilai mereka yang berkelanjutan. Arti kedua adalah repositori atau bangunan tempat materi arsip disimpan. Arti ketiga adalah agensi yang bertanggung jawab atas seleksi, 
preservasi, dokumentasi dan menyediakan materi arsip (Senturk, 2011).

Pengelolaan kearsipan pada dasarnya merupakan salah satu kegiatan yang ditujukan untuk mengelola segala dokumendokumen yang ada dalam suatu organisasi atau instansi yang dapat digunakan sebagai penunjang aktivitas organisasi tersebut dalam mencapai tujuannya. Terlebih lagi semakin mengikuti perkembangan zaman maka pengelolaan arsip menjadi berbeda pula.

Dengan kemajuan zaman yang sangat pesat ini kadang kala sebuah organisasi justru mengabaikan arti penting dari sebuah arsip, padahal kemajuan suatu organisasi memerlukan dukungan manajemen yang tepat. Untuk mengelola manajemen memerlukan data dan informasi. Salah satu sumber data adalah arsip, karena arsip adalah bukti dan rekaman kegiatan atau transaksi, mulai dari kegiatan sampai akhir kegiatan yang berhubungan dengan pengambilan keputusan karena sebuah bukti sangat bernilai bagi suatu perusahaan.

Arsip perusahaan adalah arsip yang tercipta sebagai endapan informasi terekam dari pelaksanaan tugas dan fungsisuatu perusahaan atau organisasi yang dalam operasionalnya berorientasi ekonomi.Arsip bisnis menurut Edwin Green adalah arsip tentang keputusan-keputusan dan perubahanperubahan, struktur dan personalia, kinerja serta hasil yang diperoleh suatu usaha. Betuk usaha bisnis dapat berwujud perusahaan multinasional, perusahaan nasional, perusahaan patungan, bahkan perusahaan perorangan dan arsip badan usaha (Widarno, 2015).

Menjadi jantungnya suatu perusahaan, seharusnya sistem kearsipan di kantor Berita Pagi Palembang dapat terlaksana sesuai dengan pedoman yang benar, demi meningkatkan kualitas dari sebuah perusahaan itu sendiri. Sistem kearsipan merupakan 
modal yang utama dari penyelenggaraan sebuah perusahaan.Sebuah arsip disebut sebagai tulang punggungnya perusahaan, sebab berhasil atau tidaknya penyelenggaraan sebuah perusahaan banyak ditentukan pula oleh kualitas sistem kearsipannya.

Namun adanya keberadaan unit kearsipan yang ada, baik itu dari pemerintah maupun swasta masih kurang dilaksanakan bagi organisasi-organisasi, hanya organisasi tertentulah yang memanfaatkan layanan arsip tersebut. Maka dari itu sebuah organisasi perlu memahami arti penting dari arsi dan memahami pentingnya dari Sistem Informasi Manajemen (SIM) agar pengelolaannya dapat dilaksanakan dengan baik dan tercapainya tujuan dari sebuah organisasi itu sendiri.

Pada setiap kegiatan diperlukan bantuan data dan informasi. Demikian pula pada kegiatan pengambilan keputusan yang kita kenal sebagai Sistem Informasi Manajemen (SIM). Dengan bantuan data dan informasi yang benar dan teliti maka pengambilan keputusan dapat dihasilkan secara efesien dan efektif. Didalam SIM data diolah menjadi informasi. Informasi menjadi bahan pertimbangan didalam proses pengambilan keputusan. Keputusan tersebut kemudian dijabarkan lebih lanjut dalam bentuk program atau kegiatan (Amsyah, 2003).

Demikian pula halnya dengan kegiatan kearsipan di lingkungan kantor Berita Pagi di Palembang, perlu dikelola dengan baik agar setiap pengelolan pada setiap bidang yang ada dapat dilihat secara nyata hasil kerja yang telah dicapainya, serta dapat membantu pimpinan dalam pengambilan keputusan.

Maka dari itu makalah ini dianggap perlu untuk mengetahui bagaimana pengelolaan unit kearsipan yang ada di Kantor Berita Pagi Palembang.

\section{Rumusan Masalah}


1. Bagaimana keberadaan / posisi struktural unit pengeloaan arsip di kantor Berita Pagi Palembang ?

2. Bagaimana pelaksanaan pengeloaan dan penyimpanan sistem kearsipannya ?

\section{Metodologi Penelitian}

Makalah ini menggunakan metode kualitatif dengan teknik observasi dan wawancara.Pemakalah melakukan observasi untuk melihat gambaran kejadian atau peristiwa yang terjadi dilapangan dan untuk menjawab pertanyaan.Hal ini dilakukan dengan harapan dapat memperoleh data yang lengkap dan dapat membantu penelitian ini.

Wawancara adalah pengambilan data dengan cara menanyakan sesuatu kepada seseorang responden, caranya dengan bercakap-cakap secara tatap muka. Dengan adanya wawancara ini, pemakalah melakukan pertanyaan yang sesuai dengan objek penelitian yang dapat memberikan informasi mengenai Sistem Pengelolaan Lembaga Kearsipan di Kantor Surat Kabar Berita Pagi Palembang (Nurulita, 2015).

\section{Pembahasan}

\section{Pengertian Arsip}

Arsip adalah informasi terekam dalam bentuk apapun, termasuk data dalam sisitem computer, dibuat atau diterima, dan dikelola oleh organisasi atau perseorangan dalam rangka transaksi kegiatan atau melakukan pekerjaan dan disimpan sebagai bukti kegiatan (Krihanta, 2014).

Berdasarkan Undang-undang No.7 Tahun 1971 tentang ketentuanketentuan pokok kearsipan, pasal 1, arsip adalah :

1. Naskah-naskah yang dibuat dan diterima oleh lembaga-lembaga Negara dan Badan-badan pemerintahan dalam bentuk corak 
apapun baik dalam keadaan tunggal maupun berkelompok dalam rangka pelaksanaan kegiatan pemerintahan.

2. Naskah-naskah yang dibuat dan diterima oleh Badan-badan Swasta atau perorangan, dalam bentuk corak apapun, baik dalam keadaan tunggal maupun berkelompok, dalam rangka pelaksanaan kehidupan kebangsaan (Amsyah, 2003).

Apapun sebutan dan istilahnya, yang dimaksud dengan arsip disini adalah setiap catatan (rekod/warkat) yang tertulis, tercetak, atau ketikan, dalam bentuk huruf, angka atau gambar yang mempunyai arti dan tujuan tertentu sebagai bahan komunikasi dan informasi, yang terekam pada kertas (kartu, formulir), kertas film (slide, film-strip, disket), kertas photocopy dan lain-lain.

\section{Unit Kearsipan di Berita Pagi Palembang}

Kantor Berita Berita Pagi Palembang seperti yang sudah dijelaskan, tidak mempunyai unit kearsipan khusus, Di Kantor Berita Pagi Palembang, tidak mempunyai unit khusus pengelolaan kearsipan.Melainkan sistem pengelolaan kearsipannya langsung dikelola divisi masing-masing.Yang terdiri dari divisi Iklan, produksi, percetakan, keuangan, umum dan HRD, redaksi.Yang lebih dikenal dengan sistem desentralisasi.

Pengorganisasian arsip, adalah pembagian tugas dan wewenang pengelolaan arsip dapat dilaksanakan sebaik-baiknya dalam suatu organisasi.Dengan adanya kejelasan siapa yang mengelola dan siapa yang bertanggung jawab, maka pengelolaan arsip dapat dilakukan dengan tertib menghindari saling lempar tanggung jawab (Anwari, 2005).

Setiap organisasi atau perusahaan tentu perlu memelihara dan menjaga keutuhan arsip yang dimiliki setiap perusahaan.Dengan demikian arsip perlu disimpan dengan baik agar apabila suatu saat diperlukan dapat diakses dengan cepat 
(Nurulita, 2015). Di dalam pengorganisasian arsip terdapat beberapa tipe pengorganisasian penyimpanan arsip salah satunya desentralisasi, bilamana suatu kantor atau organisasi menganut sistem pengelolaan arsip secara desentralisasi, ini berarti semua unit kerja mengelola arsipnya masing - masing.

Sistem penyimpanan yang dipergunakaan masing-masing unit kerja tergantung kepada ketentuan kantor masing-masing. Semua kegiatan kearsipan, mulai dari pencatatan, penyimpanan, peminjaman, pengawasan, dan pemusnahan dilaksanakan oleh unit kerja masing-masing dan ditempat unit kerja masing-masing.

Menurut (Amsyah, 2003) ketentuan desentralisasi arsip serta kerugiannya adalah:

1. Pengelolaan arsip dapat dilakukan sesuai kebutuhan unit kerja masing-masing.

2. Keperluan akan arsip mudah terpenuhi, karena berada pada unit kerja sendiri.

3. Penanganan arsip lebih mudah dilakukan, karena arsiparsipnya sudah dikenal baik.

Kerugian desentralisasi arsip adalah:

1. Penyimpanan arsip tersebar diberbagai lokasi, dan dapat menimbulkan duplikasi arsip yang disimpan.

2. Kantor harus menyediakan peralatan dan perlengkapan arsip disetiap unit kerja, sehingga penghematan pemakaian peralatan dan perlengkapan sukar dijalanka.

3. Penataran dan latihan kearsipan perlu diadakan karena perugas-pegutas umumnya bertugas rangkap dan tidak mempunyai latar belakang pendidikan kearsipan.

4. Kegiatan pemusnahan arsip harus dilakukan setiap unit kerja, dan ini merupakan pemborosan kerja.

\section{Organisasi Perusahaan di Kantor Berita Pagi Palembang}

Dalam hal ini, Kantor Berita Pagi Palembang khususnya menerapkan bidang-bidang dibawah ini : 


\section{a. Korporasi}

Menunjukkan fungsi suatu badan yang mengatur dirinya dalam administrasi perusahaan, organisasi dan operasi sebagai suatu bisnis yang legal. Dalam kantor Berita Pagi Palembang, lebih mengutamakan kegiatan operasi suatu bisnis yang legal. Misalnya Koran.

b. Hukum

Fungsi ini meliputi urusan perusahaan mulai dari masalah yang berkaitan dengan pemilikan/penempatan aset, pelaksanaan kegiatan komersil dan industri, pengelolaan kekayaan perusahaan, sampai urusan yang berkaitan dengan perkara hukum perusahaan, dan produk hukum perusahaan.

c. Produksi

Fungsi ini meliputi perencanaan produksi, proses produksi, service produksi, dan pengawasan produksi. Di Kantor Berita Pagi Palembang, tugas dan fungsi karyawan dibagi menjadi beberapa bidang salah satunya bidang produksi. Dalam hal ini tugas bagian produksi meliputi percetakan dan penerbitan.

d. Keuangan

Fungsi ini bertanggung jawab atas pengendalian keuangan perusahaan dari kegiatan perencanaan anggaran dan kerja tahunan, implementasi, kontrol dan monitoring kegiatan, serta kebijakan keuangan yang meliputi akuntansi dan audit dari pendapatan, pengeluaran, aset, dan utang.

e. Marketing

Fungsi ini bertanggung jawab atas penjualan hasil produksi barang/jasa, yang meliputi kegiatan distribusi ke agen, dealer, grosir, pengecer atau bahkan ke konsumen langsung. Di kantor Berita Pagi Palembang, agen yang utama dalam 
memasarkan Koran/surat kabar yaitu masyarakat sekitar, toko-toko, kantor dan sebagainya.

f. Sumber Daya Manusia

Fungsi ini bertanggung jawab atas pengelolaan pegawai mulai dari saat penerimaan, pembinaan, pendidikan dan latihan peningkatan kesejahteraan, sampai jaminan tua.

g. Penyelenggaraan Dokumen Perusahaan

Fungsi ini bertanggung jawab atas terselenggaranya pengelolaan arsip dengan efektif dan efisien. Fungsi ini terkait dengan penciptaan, penggunaan arsip dan penyusutan arsip.

\section{Sistem Pengelolaan Arsip di Kantor Berita Pagi Palembang}

Sistem kearsipan adalah suatu sistem, metode atau cara yang dipergunakan dalam penyimpanan dan penemuan kembali arsip/dokumen (Amsyah, 2003). Meliputi kegiatan planning, organizing, actuating dan controlling.Agar sistem arsip dapat berjalan secara efektif dan efisien, maka harus berpedoman pada ciri penyelenggaraan sistem arsip yang baik yaitu :

1. Mengurus sedikit warkat/arsip.

2. Warkat yang berkualitas.

3. Warkat yang selektif.

4. Dapat menghemat biaya, tenaga, dan waktu.

Dapat disimpulkan sistem pengelolaan arsip adalah paduan tata cara yang sistematis dalam mengolah arsip agar tersimpan dengan aman dan dapat ditemukan dengan mudah sewaktu diperlukan. Sistem pengelolaan arsip yang baik harus sesuai dengan kondisi organisasi, sederhana, mudah dimengerti dan mudah dioperasikan, mudah diadaptasikan bila ada perubahan sistem serta fleksibel dan elastis untuk menampung perkembangan, murah, aman, akurat (Widarno, 2015).

Pada Kantor Berita Pagi Palembang, sistem pengelolaan kearsipan tidak mengikuti pedoman pengelolaan khusus. Dikarenakan tidak mempunyai seorang arsiparis, jadi yang 
mengelola sistem kearsipannya yaitu orang-orang yang bekerja dibagian divisi saja yang mana tadi telah dijelaskan bidang-bidang divisi yang ada di Kantor Berita Pagi Palembang.

Salah satunya bidang divisi periklanan.Ketika arsip bagian periklanan masuk atau ada orang yang ingin meminta bantuan promosi, petugas yang berkepentingan dibidang tersebut langsung menginput data melalui Microsoft excel dan Microsoft word. Untuk sistem pengolahannya, perusahaan ini mengolah arsip-arsip yang masuk berdasarkan tanggal setiap harinya.

\section{Ruang Lingkup Sistem Pengelolaan Arsip}

Ruang lingkup sistem pengelolaan arsip dalam penelitian ini meliputi:

1. Penciptaan Arsip: Menurut ANRI Pencipta Arsip adalah "pihak yang mempunyai kemandirian dan otoritas dalam pelaksanaan fungsi, tugas dan tanggung jawab di bidang pengelolaan arsip dinamis". ANRI (ANRI pasal 1 nomor 25 tahun 2012). Sejak arsip diciptakan, dikantor Berita Pagi Palembang, arsip berupa Koran atau dokumen lainnya dikelola oleh masing-masing bidang.

2. Penyimpanan Arsip: Penyimpanan arsip adalah pekerjaan yang dilaksanakan pada penyimpanan sebuah surat agar penemuan surat yang sudah disimpan dapat dilakukan dengan cepat apabila surat tersebut sewaktu-waktu diperlukan (Amsyah, 2003).

3. Penyusutan Arsip: Penyusutan arsip adalah kegiatan pengurangan jumlah arsip dengan cara pemindahan arsip inaktif dari unit pengolah ke Unit Kearsipan, pemusnahan arsip yang tidak memiliki nilai guna, dan penyerahan arsip statis kepada lembaga kearsipan. (ANRI pasal 1 nomor 25 tahun 2012).

4. Pemusnahan Arsip: Pemusnahan Arsip adalah "kegiatan memusnahkan arsip yang tidak mempunyai nilai kegunaan 
dan telah melampaui jangka waktu penyimpanan" (ANRI pasal 1 nomor 25 tahun 2012) (Rachmad Fuji, dkk, 2013).

Pemusnahan arsip adalah kegiatan memusnahkan arsip yang tidak mempunyai nilai kegunaan dan telah melampau jangka waktu penyimpanan (Jumiyati, 2010) Berita Pagi Palembang tidak menerapkan penyusutan dan pemusnahan arsip/Koran, melainkan Koran yang tidak laku kembali dijual kembali oleh agen atau dikilo kan di pasaran. Namun mereka menyimpan format digital atau file nya dikomputer dengan cara discan.

Pengaksesan arsip surat kabar Kantor Berita Pagi Palembang dapat dikategorikan ke dalam dua jenis. jenis pertama berdasarkan frekuensi penggunaannya dapat dikategorikan ke dalam arsip inaktif karena penggunaannya sudah menurun. Jenis kedua berdasarkan langsung atau tidak langsung, maka dapat pula dikategorikan dalam arsip statis karena arsip ini memiliki nilai guna kesejarahan sehingga penggunaannya secara langsung sangat dibatasi (Sadhyoko, 2014).

\section{Sistem Penyimpanan Arsip di Kantor Berita Pagi Palembang}

Pada dasarnya ,penyimpanan arsip dilakukan dengan menggunakan cara tertentu secara sistematis yang dimaksudkan untuk membantu dan mempermudah kita dalam penyimpanan dan penemuan kembali arsip tersebut. Metode penyimpanan yang sistematis tersebut sering disebut dengan sistem penyimpanan arsip (filing system). Sistem penyimpanan dapat didefinisikan sebagai sistem pengelolaan dan penemuan kembali arsip berdasarkan pedoman yang telah dipilih untuk meningkatkan efektifitas dan efesiensi penggunaan waktu, tempat, tenaga, dan bi aya. Salah satu bentuk sistem penyimpanan tersebut adalah sistem penyimpanan arsip (dokumen - dokumen dan surat- surat) berdasarkan tanggal (Sukaryanto, 2004). 
Sistem tanggal adalah sistem penyimpanan dan penemuan kembali arsip berdasarkan tanggal, bulan, atau tahun. Dalam sistem ini yang dijadikan kode penyimpanan dan penemuan kembali adalah tanggal, bulan, atau tahun pembuatan surat atau tanggal surat yang tercantum pada barisan tanggal yang tercantum dalam arsip itu sendiri. Sistem tanggal merupakan sistem yang paling sederhana dan praktis sehingga cocok diterapkan kepada perusahaan kecil yang kegiatannya masih sedikit dan masalahnya belum kompleks (Sukaryanto, 2004).

Setiap permintaan arsip harus tercatat, siapapun yang meminjam arsip yang dibutuhkan baik yang meminjam secara langsung oleh orang yang bersangkutan ataupun diwakilkan agar arsip-arsip yang dimiliki dapat terkendali dan mudah untuk ditemukan kembali.Pencatatan arsip yang dipinjam dapat dilakukan pada sebuah kartu yang disebut dengan kartu peminjaman (Rusdawati, Ardoni, 2014).

Pada Kantor Berita Pagi Palembang dalam sistem penyimpanan arsipnya menggunakan sistem tanggal atau disebut sistem kronologis. Pengelompokan tetap dilaksanakan atas sistem subjek, subsubjek, dan satuan subsubjek yang dijadikan pengelompokan itu adalah tanggal, bulan, dan tahun yang tercantum pada barisan tanggal surat. Subyek disini bagian periklanan, dari periklanan lalu dibuatkan subsubyek nya lagi menjadi promosi bisnis butik, dari subsubyek ini lebih dirincikan lagi menjadi subsubsubyek yaitu koleksi dari butik seperti pakaian, jilbab, sepatu.ketiga sub tersebut kemudian disusun berdasarkan tanggal, bulan, dan tahunnya.

Dan yang mengelola ini di kantor Berita Pagi Palembang yaitu sesuai subyek yang dibutuhkan diantaranya divisi periklanan, produksi, percetakan, keuangan, umum dan HRD.

Dari uraian di atas dapat diambil suatu kesimpulan sebagai berikut. 
1. Tahun ditetapkan sebagai judul laci.

2. Bulan ditetapkan sebagai judul guide.

3. Tanggal ditetapkan sebagai judul folder (Sukaryanto, 2004).

Seperti halnya di kantor Berita Pagi yang menerapkan sistem penyimpann desentralisasi, disetiap masing-masing unit kerja menyimpan arsipnya sendiri, misalnya unit pemasaran Pada kantor surat kabar Berita Pagi disana belum mempunyai satu unit kearsipan yang khusus mengelola arsip di kantor tersebut, menurut data yang di dapatkan pada kantor surat kabar berita pagi tidak ada sama sekali satupun unit kearsipan menurut hasil wawancara dengan salah satu staf yang ada, disana hanya mengandalkan penyimpanan arsip per bidang kerja misalnya bidang keungan jadi arsip tentang keungan hanya di simpan di bidang tersebut. Dengan kata lain disana menerapkan penyimpanan dengan tipe desentralisasi (Amsyah, 2003).

\section{Kesimpulan}

Setelah dilakukan observasi di Kantor Berita Pagi Palembang, dapat disimpulkan bahwa di kantor berita pagi menerapkan sistem penyimpann desentralisasi, disetiap masingmasing unit kerja menyimpan arsipnya sendiri.

Dalam sistem pengelolaan arsipnya, kantor Berita Pagi Palembang tidak menerapkan penyusustan dan pemusnahan arsip/Koran, melainkan Koran yang tidak laku kembali dijual kembali oleh agen atau dikilo kan di pasaran. Namun mereka menyimpan format digital atau file nya di komputer dengan cara discan. Untuk penyimpanan mereka hanya mengandalkan hardisk untuk menyimpan hasil scan dari koran yang ada agar jika suatu saat diperlukan akan dengan mudah ditemukan, tetapi jika terjadi bencana terhadap hardisk mereka tidak mempunyai backup data dan jika hardisk itu rusak data yang ada akan hilang begitu saja. 


\section{Daftar Pustaka}

Amsyah, Z. (2003). manajemen kearsipan. jakarta: gramedia pustaka utama.

Anwari, A. (2005). Manajemen Kearsipan dalam Penyelenggaraan Organisasi Publik. Medani, 30.

Apallidya, dkk. (2009). Kesiapsiagaan Dalam Mengantisipasi Bencana di Perpustakaan dan Pusat Arsip. Baca, 8.

Basuki, S. (2015). Pengantar Ilmu Kearsipan. Jakarta: Universitas Terbuka.

Jimerson, R. C. (2003). Archives and Memory. OCLC Systems \& Services: International digital library perspectives, 91.

Jumiyati, E. (2010). Penyusutan Arsip di Pusat Teknologi Bahan Bakar Nuklir. Pusat Teknologi Bahan Bakar Nuklir, 68.

Krihanta. (2014). pengelolaan arsip vital. tanggerang selatan: universitas terbuka.

Nurulita, A. (2015). Sistem Pengelolaan Arsip Dinamis Pada Administrasi Perkantoran di Biro Umum Sekretariat Jendral Kementrian Jendral Umum Republik Indonesia. Program Studi Ilmu Perpustakaan Universitas Negeri Islam Syarif Hidayatullah, 30.

Rachmad Fuji, dkk. (2013). Sistem Pengelolaan Arsip di Dinas Pekerjaan Umum Bina Marga dan Pematusan Kota Surabaya. Fakultas Ekonomi, Universitas Negeri Surabaya, 7.

Rusdawati, Ardoni. (2014). Sistem Penyimpanan dan Prosedur Temu Kembali Arsip Dinamis Aktif di Kantor Sekretariat DPRD Provinsi Sumatrera Barat. Ilmu Informasi Perpustakaan dan Kearsipan, 29-30.

Sadhyoko, J. A. (2014). Menciptakan Pengelolaan Arsip Surat Kabar yang Andal. Opini, 8-9.

Sanjuli, R. F. (2015). Sistem Pengelolaan Arsip di Dinas Pekerjaan Umum Bina Marga dan Pematusan Kota Surabaya. 
Administrasi Perkantoran, 8.

Senturk, B. (2011). The Concept Of User Satisfaction in Archival Institusions. Department of Information and Records Management, 68.

Sukaryanto, T. (2004). Mengelola Dokumen Dengan Sistem Tanggal. Jakarta: Direktorat Pendidikan Menengah Kejuruan.

Widarno. (2015). Materi Pokok Organisasi Tata Laksana dan Lembaga Kearsipan. Tangerang Selatan: Universitas Terbuka.

Wursanto. (2005). Kearsipan II. Yogyakarta: Kanisius. 